\title{
Obstructive Sleep Apnea in Patients with Chronic Obstructive Pulmonary Disease
}

\author{
Pantaree Aswanetmanee MD, Chok Limsuwat MD
}

\begin{abstract}
Obstructive sleep apnea (OSA) and chronic obstructive pulmonary disease (COPD) are common disorders in clinical practice and are associated with significant cardiovascular morbidity. The simultaneous occurrence of OSA and COPD happens frequently and is referred to as an overlap syndrome. These patients often have very poor quality sleep and more nocturnal hypoxemia. This combination may increase the severity of metabolic complications and cardiovascular disease, and these patients have increased mortality when compared to patients with either COPD or OSA alone. The treatment of overlap syndrome should focus on both coexisting diseases and includes continuous positive airway pressure, oxygen supplementation, and medications for chronic lung disease.
\end{abstract}

Key words: COPD, obstructive sleep apnea, hypoxemia, overlap syndrome

\section{INTRODUCTION}

Obstructive sleep apnea (OSA) is characterized by recurrent upper airway closure during sleep and affects $5-20 \%$ of the adult population in the United States ${ }^{1}$. These patients have frequent cessation or reduction in airflow during sleep with consequent blood oxygen desaturation and sleep fragmentation. OSA is a potential risk factor for multiple diseases, including ischemic heart disease, stroke, hypertension, metabolic syndrome, and diabetes.

Corresponding author: Chok Limsuwat, MD Contact Information: chok.limsuwat@gmail.com DOI: 10.12746/swrccc2014.0207.096
Chronic obstructive pulmonary disease (COPD) is also a common clinical disorder and occurs in 4-6\% of the adult population in the United States ${ }^{2}$. COPD is characterized by chronic airflow obstruction secondary to chronic bronchitis and/or emphysema and is associated with significant morbidity and mortality 3 . Patients with COPD often have poor sleep quality, nocturnal oxygen desaturation, especially during REM sleep, and comorbid sleep-related breathing disorders ${ }^{4}$.

The simultaneous occurrence of OSA and COPD is common, is called an overlap syndrome, and increases the likelihood of heart failure, pulmonary hypertension, and systemic hypertension ${ }^{5}$. This overlap syndrome occurs in approximately $1 \%$ of adults ${ }^{6}$ and $10-20 \%$ of patients with OSA ${ }^{7}$. However, it is un- 
clear whether the coexistence of these two disorders has additive or synergistic adverse effects and what level of abnormality in either disorder is consequential when combined with the other disorder.

\section{Consequence of OVERLAP SYNDROME}

\section{Sleep in the overlap syndrome}

A cross-sectional study in five European countries found $78.1 \%$ of patients with COPD reported some degree of nocturnal symptoms ${ }^{8}$. COPD patients report difficulty falling asleep, difficulty maintaining sleep, and increased daytime sleepiness, and frequently have nocturnal hypoxemia. The mechanisms for nocturnal oxygen desaturation in patients with COPD include alveolar hypoventilation, reduction in the functional residual capacity, increased ventilation perfusion mismatch, and increased upper airway resistance. During REM sleep the $\mathrm{PaO}_{2}$ can decrease to levels as low as $20 \mathrm{mmHg}{ }^{9}$. Patients with OSA have cyclical desaturation associated with apneas and hypopneas and sleep fragmentation. The degree of desaturation depends on the body habitus (BMI) and any coexisting alteration in lung function. Therefore, nocturnal hypoxemia is a frequent and important pathophysiological event in patients with the overlap syndrome and is associated with sleep arousals, fragmentation, decreased rapid eye movement (REM) sleep stage, and fluctuations in pulmonary artery and systemic pressures ${ }^{10}$. The Sleep Heart Health Study is a prospective multicenter cohort study designed to determine whether OSA is a risk factor for hypertension and cardiovascular events. This study did not find an association between mild COPD disease and OSA but demonstrated that subjects with both OSA and obstructive airway disease defined by spirometry were more likely to have low oxygen saturations at night ${ }^{11}$.

\section{Systemic inflammation in overlap syndrome}

OSA and COPD are both associated with systemic inflammation, and activation of inflammatory cells and associated cascades lead to endothelial dysfunction and atherosclerosis ${ }^{12}$. The combination of hypoxemia and hypercapnia may increase the en- dothelial response to inflammatory cytokines, such as interleukin-1, interleukin-6, and tumor necrosis factor alpha, that cause chronic systemic inflammation and increase the risk of cardiovascular disease ${ }^{13,14}$.

\section{Cardiovascular disease in overlap syndrome}

Patients with OSA develop intermittent hypoxemia, sleep fragmentation, increased sympathetic activity, and changes in the hypothalamic pituitary axis that lead to systemic inflammation ${ }^{15,16}$. Repetitive hypoxemia and oxidative stress also occur and cause insulin resistance and promote cardiovascular disease. COPD causes chronic inflammation in lung tissue; the extent of this inflammatory process correlates with the severity of the disease. Chronic inflammation in the lung parenchyma leads to systemic inflammation, oxidative stress, and endothelial dysfunction. These mechanisms promote the cardiovascular diseases ${ }^{17}$. Since both OSA and COPD cause systemic inflammation, patients with the overlap syndrome might have more systemic inflammation with more adverse metabolic and vascular consequences than patients with either diagnosis alone. However, most studies do not have an adequate design or size to address these outcomes and more prospective studies are needed to prove this possibility.

\section{Quality of life in the overlap syndrome}

Both COPD and OSA have well defined effects on health-related quality of life ${ }^{18,19}$. When these two conditions coexist, there is potentially more desaturation during sleep and more sleep disruption, which could lead to a worse quality of life. Mermigkis compared quality of life in patients with overlap syndrome and with COPD alone and found a markedly impaired quality of life in the overlap syndrome group ${ }^{20}$.

\section{Mortality in the overlap syndrome}

Marin et al reported that patients with untreated overlap syndrome have an increased risk of death from any cause, cardiovascular deaths, and hospitalization because of COPD exacerbations. They found that death from any cause occurred in 213 patients $(32.7 \%)$ over a median follow-up of 9.4 years ${ }^{21}$. An- 
other study also reported that patients with the overlap syndrome have a lower five year survival rate than patients with OSA alone ${ }^{22}$. The causes of death include COPD exacerbations, pulmonary hypertension with right heart disease, cardiac arrhythmias, coronary syndromes, and other diagnoses associated with cigarette smoking.

\section{DIAGNOSIS AND SCREENING}

Patients with COPD with clinical risk factors for OSA, such as snoring, obesity, daytime sleepiness, or significant weight gain, need additional evaluation for a sleep-related breathing disorder ${ }^{23}$. The measurement of oxygen saturation by pulse oximetry overnight is an excellent screening tool for sleep-related breathing disorders ${ }^{24}$, but polysomnography is the standard diagnostic test for OSA in all patients. Patients with OSA and daytime hypoxemia and/or hypercapnea should have pulmonary evaluation with pulmonary function testing. Patients with either COPD or OSA with unexpectedly high pulmonary artery pressures should be evaluated for the overlap syndrome.

\section{TREATMENT}

Alterations in nocturnal gas exchange, particularly oxygen desaturation, are important clinical problems in patients with overlap syndrome. The treatment of the overlap syndrome requires the treatment of OSA and COPD to maintain adequate ventilation and oxygenation at night.

\section{Positive airway pressure}

CPAP is the standard treatment for OSA and is the appropriate treatment for overlap syndrome. Treatment of OSA with continuous positive airway pressure (CPAP) significantly reduces non-fatal and fatal cardiovascular events ${ }^{25}$. CPAP treatment has never been proven beneficial in patients with COPD alone but does improve outcomes in patients with OSA and COPD ${ }^{21}$. Recent studies on the long term use of CPAP in overlap syndrome have suggested mortality benefits in these patients ${ }^{26}$. Michael and colleagues did a post hoc analysis of a 2007-2010 outpatient database of 10,272 patients. Of these, 227 patients had overlap syndrome, and 17 of them died $(7.4 \%)$. Longer treatment times with CPAP were associated with reduced mortality (HR $0.71, p<0.001)$ 27. Another recent cohort study demonstrated that CPAP mitigates the excess risk of mortality in hypercapnic patients but not in normocapnic patients with the overlap syndrome ${ }^{28}$. Noninvasive ventilation has been considered a good treatment option in the overlap syndrome, but multiple small studies have had inconsistent results with this treatment.

Oxygen

Oxygen is the standard long treatment of COPD with hypoxemia. Patients with overlap syndrome have worse hypoxemia during the night ${ }^{9}$. Therefore, careful assessment of oxygen saturation after CPAP titration is essential as some of these patients also require supplemental $\mathrm{O}_{2}$. In addition, supplemental oxygen for at least 15 hours per day during the day to correct any daytime hypoxemia is recommended. This therapy reduces mortality, reduces pulmonary artery pressures, and improves neurological outcomes ${ }^{29}$.

\section{Medication}

Treatment of underlying COPD with bronchodilators and inhaled corticosteroids improves nocturnal oxygen saturations in patients with COPD. Studies with tiotropium and long-acting beta-agonists have shown that both drugs improved nocturnal oxygen saturations ${ }^{30,31}$. In the overlap syndrome hypoxemia is significantly worse during sleep. Therefore, intensive treatment of both COPD and OSA should improve oxygenation, improve cardiovascular outcomes, and reduce mortality in this syndrome.

\section{KEY POINTS}

1. Patients with OSA frequently have COPD, and patients with COPD frequently have OSA.

2. These patients with an overlap syndrome can have significant nocturnal hypoxemia and increased cardiovascular morbidity and mortality.

3. They need evaluation for both disorders and treat- 
ment with CPAP if the OSA meets the usual criteria for treatment. They may require supplemental oxygen even if CPAP titration is successful.

KEY wORDs: COPD, obstructive sleep apnea, hypoxemia, overlap syndrome

\section{REFERENCES}

1. Young T, Peppard PE, Gottlieb DJ. Epidemiology of obstructive sleep apnea: a population health perspective. Am J Respir Crit Care Med. 2002 May 1;165(9):1217-39.

2. Qaseem A, Wilt TJ, Weinberger SE, Hanania NA, Criner G, van der Molen T, et al. Diagnosis and management of stable chronic obstructive pulmonary disease: a clinical practice guideline update from the American College of Physicians, American College of Chest Physicians, American Thoracic Society, and European Respiratory Society. Ann Intern Med. 2011 Aug 2;155(3):179-91.

3. Pauwels R. Global initiative for chronic obstructive lung diseases (GOLD): time to act. European Respiratory Journal. 2001 Dec;18(6):901-2.

4. Fleetham J, West P, Mezon B, Conway W, Roth T, Kryger M. Sleep, Arousals, and Oxygen Desaturation in Chronic Obstructive Pulmonary-Disease - the Effect of Oxygen-Therapy. American Review of Respiratory Disease. 1982;126(3):429-33.

5. Chaouat A, Weitzenblum E, Krieger J, Ifoundza T, Oswald M, Kessler R. Association of chronic obstructive pulmonary disease and sleep apnea syndrome. Am J Respir

Crit Care Med. 1995 Jan;151(1):82-6.

6. McNicholas WT. Chronic obstructive pulmonary disease and obstructive sleep apnea: overlaps in pathophysiology, systemic inflammation, and cardiovascular disease. Am J Respir Crit Care Med. 2009 Oct 15;180(8):692-700.

7. Lopez-Acevedo MN, Torres-Palacios A, Elena Ocasio-Tascon M, Campos-Santiago Z, Rodriguez-Cintron W. Overlap syndrome: an indication for sleep studies? : A pilot study. Sleep \& breathing = Schlaf \& Atmung. 2009 Nov;13(4):409-13.

8. Price D SM, Milligan G. The prevalence and impact of night-time symptoms in COPD patients - results of across-sectional study in five European countries. Proc of the IV World Asthma and COPD Forum 20112011.

9. Fletcher EC, Scott D, Qian W, Luckett RA, Miller $\mathrm{CC}$, Goodnight-White S. Evolution of nocturnal oxyhemoglobin desaturation in patients with chronic obstructive pulmonary disease and a daytime $\mathrm{PaO} 2$ above $60 \mathrm{~mm} \mathrm{Hg}$. Am Rev Respir Dis. 1991 Aug;144(2):401-5.

10. Fleetham J, West P, Mezon B, Conway W, Roth T, Kryger M. Sleep, arousals, and oxygen desaturation in chronic obstructive pulmonary disease. The effect of oxygen therapy. Am Rev Respir Dis. 1982 Sep;126(3):429-33.

11. Sanders MH, Newman AB, Haggerty CL, Redline S, Lebowitz M, Samet J, et al. Sleep and sleep-disordered breathing in adults with predominantly mild obstructive airway disease. Am J Respir Crit Care Med. 2003 Jan 1;167(1):7-14.

12. Dumitrascu R, Heitmann J, Seeger W, Weissmann N, Schulz R. Obstructive sleep apnea, oxidative stress and cardiovascular disease: lessons from animal studies. Oxidative Medicine and Cellular Longevity. 2013;2013:234631. PubMed

13. Wouters EF. Local and systemic inflammation in chronic obstructive pulmonary disease. Proceedings of the American Thoracic Society. 2005;2(1):26-33.

14. Ryan S, Taylor CT, McNicholas WT. Systemic inflammation: a key factor in the pathogenesis of cardiovascular complications in obstructive sleep apnoea syndrome? Postgraduate Medical Journal. 2009 Dec;85(1010):693-8.

15. Harris M, Glozier N, Ratnavadivel R, Grunstein RR. Obstructive sleep apnea and depression. Sleep Medicine Reviews. 2009 Dec;13(6):437-44.

16. Buckley TM, Schatzberg AF. On the interactions of the hypothalamic-pituitary-adrenal (HPA) axis and sleep: normal HPA axis activity and circadian rhythm, exemplary sleep disorders. J Clin Endocrinol Metab. 2005 May;90(5):3106-14.

17. Marchetti N, Ciccolella DE, Jacobs MR, Crookshank A, Gaughan JP, Kashem MA, et al. Hospitalized acute exacerbation of COPD impairs flow and nitroglycerin-mediated peripheral vascular dilation. COPD. 2011 Apr;8(2):60- 
5.

18. Goncalves MA, Paiva T, Ramos E, Guilleminault C. Obstructive sleep apnea syndrome, sleepiness, and quality of life. Chest. 2004 Jun;125(6):2091-6.

19. Engleman HM, Douglas NJ. Sleep. 4: Sleepiness, cognitive function, and quality of life in obstructive sleep apnoea/hypopnoea syndrome. Thorax. 2004 Jul;59(7):618-22.

20. Mermigkis C, Kopanakis A, Foldvary-Schaefer N, Golish J, Polychronopoulos V, Schiza S, et al. Health-related quality of life in patients with obstructive sleep apnoea and chronic obstructive pulmonary disease (overlap syndrome). Int J Clin Pract. 2007 Feb;61(2):207-11.

21. Marin JM, Soriano JB, Carrizo SJ, Boldova A, Celli BR. Outcomes in patients with chronic obstructive pulmonary disease and obstructive sleep apnea: the overlap syndrome. Am J Respir Crit Care Med. 2010 Aug 1;182(3):32531.

22. Chaouat A, Weitzenblum E, Krieger J, Sforza E, Hammad H, Oswald M, et al. Prognostic value of lung function and pulmonary haemodynamics in OSA patients treated with CPAP. Eur Respir J. 1999 May;13(5):1091-6.

23. Penzel T, Peter JH. Ambulatory diagnosis of sleep-related breathing disorders. Sleep. 1992 Dec;15(6 Suppl):S9-12.

24. Tobert DG, Gay PC. New directions for pulse oximetry in sleep disorders. Mayo Clin Proc. 1995 Jun;70(6):5912.

25. Marin JM, Carrizo SJ, Vicente E, Agusti AG. Longterm cardiovascular outcomes in men with obstructive sleep apnoea-hypopnoea with or without treatment with continuous positive airway pressure: an observational study. Lancet. 2005 Mar 19-25;365(9464):1046-53.

26. Machado MC, Vollmer WM, Togeiro SM, Bilderback AL, Oliveira MV, Leitao FS, et al. CPAP and survival in moderate-to-severe obstructive sleep apnoea syndrome and hypoxaemic COPD. Eur Respir J. 2010 Jan;35(1):132-7.

27. Stanchina ML, Welicky LM, Donat W, Lee D, Corrao W, Malhotra A. Impact of CPAP use and age on mortality in patients with combined COPD and obstructive sleep apnea: the overlap syndrome. Journal of clinical sleep medicine : JCSM : official publication of the American Academy of Sleep Medicine. 2013;9(8):767-72.

28. Jaoude P, Kufel T, El-Solh AA. Survival Benefit of CPAP Favors Hypercapnic Patients with the Overlap Syndrome. Lung. 2014 Apr;192(2):251-8.

29. Continuous or nocturnal oxygen therapy in hypoxemic chronic obstructive lung disease: a clinical trial. Nocturnal Oxygen Therapy Trial Group. Ann Intern Med. 1980 Sep;93(3):391-8.

30. McNicholas WT, Calverley PM, Lee A, Edwards JC, Tiotropium Sleep Study in CI. Long-acting inhaled anticholinergic therapy improves sleeping oxygen saturation in
COPD. Eur Respir J. 2004 Jun;23(6):825-31.

31. Ryan S, Doherty LS, Rock C, Nolan GM, McNicholas WT. Effects of salmeterol on sleeping oxygen saturation in chronic obstructive pulmonary disease. Respiration; international review of thoracic diseases. 2010;79(6):475-81. 